\title{
Managing Oral Phosphate Binder Medication Expenditures Within the Medicare Bundled End-Stage Renal Disease Prospective Payment System: Economic Implications for Large U.S. Dialysis Organizations
}

\author{
Haesuk Park, PhD; Karen L. Rascati, PhD; and Michael S. Keith, PhD, PharmD
}

\begin{abstract}
BACKGROUND: From January 2016, payment for oral-only renal medications (including phosphate binders and cinacalcet) was expected to be included in the new Medicare bundled end-stage renal disease (ESRD) prospective payment system (PPS). The implementation of the ESRD PPS has generated concern within the nephrology community because of the potential for inadequate funding and the impact on patient quality of care.

OBJECTIVE: To estimate the potential economic impact of the new Medicare bundled ESRD PPS reimbursement from the perspective of a large dialysis organization in the United States.

METHODS: We developed an interactive budget impact model to evaluate the potential economic implications of Medicare payment changes to large dialysis organizations treating patients with ESRD who are receiving phosphate binders. In this analysis, we focused on the budget impact of the intended 2016 integration of oral renal drugs, specifically oral phosphate binders, into the PPS. We also utilized the model to explore the budgetary impact of a variety of potential shifts in phosphate binder market shares under the bundled PPS from 2013 to 2016.
\end{abstract}

RESULTS: The base model predicts that phosphate binder costs will increase to $\$ 34.48$ per dialysis session in 2016 , with estimated U.S. total costs for phosphate binders of over $\$ 682$ million. Based on these estimates, a projected Medicare PPS $\$ 33.44$ reimbursement rate for coverage of all oral-only renal medications (i.e., phosphate binders and cinacalcet) would be insufficient to cover these costs. A potential renal drugs and services budget shortfall for large dialysis organizations of almost \$346 million was projected.

CONCLUSIONS: Our findings suggest that large dialysis organizations will be challenged to manage phosphate binder expenditures within the planned Medicare bundled rate structure. As a result, large dialysis organizations may have to make treatment choices in light of potential inadequate funding, which could have important implications for the quality of care for patients with ESRD.

J Manag Care Spec Pharm. 2015;21(6):507-14

Copyright $\odot 2015$, Academy of Managed Care Pharmacy. All rights reserved.

\section{What is already known about this subject}

The new Medicare payment system planned to integrate Part $\mathrm{D}$ renal medications into the Medicare Part B end-stage renal disease (ESRD) bundled reimbursement package in 2014, then delayed implementation to 2016, and now, as of March 2014, has been deferred to 2024 .
Integrating Part D drugs into Part B payments at this scale is believed to lack any policy precedent, and there is concern regarding the potential for inadequate funding and reduction in quality of care.

\section{What this study adds}

Our model predicts that the projected $\$ 33.44$ prospective payment system reimbursement rate for oral-only renal medications would be insufficient to cover these costs.

This study estimates that a reimbursement rate closer to $\$ 50.91$ per dialysis session ( $\$ 34.48$ phosphate binders; $\$ 16.43$ cinacalcet) may be required simply to fund the current utilization mix of phosphate binders.

The outputs from our model support concern for potential underfunding of ESRD treatment and the management of new tradeoffs affecting the facilities and patient outcomes under the new Medicare payment approach.

$\mathrm{H}$ yperphosphatemia, a common disorder in patients with end-stage renal disease (ESRD) who are undergoing dialysis, is strongly associated with cardiovascular morbidity and mortality. ${ }^{1-3}$ For the management of hyperphosphatemia, most patients are prescribed phosphate binders to be taken 3 times per day, and doses are titrated until target serum phosphate levels (e.g., $\leq 5.5$ milligrams per deciliter) are achieved. ${ }^{4,5}$ Dialysis (hemodialysis and peritoneal dialysis) patients are generally eligible for Medicare benefits beginning in the fourth month after diagnosis of ESRD. ${ }^{6}$ The 2012 U.S. Renal Data System (USRDS) report estimates that $72 \%$ of patients undergoing hemodialysis and 64\% of patients undergoing peritoneal dialysis receive Medicare Part D coverage. ${ }^{7}$ For a dialysis organization, the per-person-per-month costs of Part $\mathrm{D}$ medications are considerably higher for phosphate binders (\$331.92, 2010 data) than for other oral renal disease medications (vitamin D, \$29.52; cinacalcet, \$99.10; 2010 data). ${ }^{7}$

In January 2011, the Centers for Medicare \& Medicaid Services (CMS) fundamentally changed payment for dialysis services for patients with ESRD on Medicare by launching a new case mix-adjusted bundled prospective payment system (PPS). ${ }^{8-10}$ At present, Medicare reimburses health care 
organizations separately for services, lab tests, injectable medications, oral vitamin D (Part B), and oral-only renal medications (Part D) provided to patients enrolled in the program. From January 2016, payment for oral-only renal medications (including phosphate binders and cinacalcet) was expected to be integrated into the Medicare Part B ESRD bundled reimbursement package after a previous 2-year delay. ${ }^{11}$ However, in March 2014, as part of the American Taxpayer Relief Act, inclusion of these drugs into the bundle has been deferred to 2024 to ensure that patients continue to have access to essential medications. ${ }^{12}$ CMS originally proposed that the 2011 bundle would include $\$ 14$ to cover oral renal medications, but organizations agreed that the proposed reimbursement for oral medications grossly underestimated actual expense and instead proposed $\$ 45 .^{13}$

The implementation of this type of bundled PPS is expected to lead to pronounced adjustments in the treatment patterns of patients with ESRD. ${ }^{9,14,15}$ For example, the bundled PPS is expected to affect the choice of dialysis type, creating financial incentives for increased use of peritoneal dialysis. ${ }^{16}$ Early observations of small dialysis organizations have suggested that intravenous vitamin D use has decreased, and use of oral therapies for metabolic bone disease has increased following implementation of the PPS in 2011 (before the integration of oral medications in the bundle). ${ }^{17}$ To our knowledge, however, no studies have investigated the budgetary impact of the PPS on large dialysis organizations or evaluated the potential financial implications of the integration of Part D oral drugs into a bundled payment. Previous studies raised concerns that integrating Part D oral drugs with Part B payments lacks any policy precedent, which may result in potential inadequate funding and reduction in quality of care. , $^{911,13,15}$ However, no quantitative evaluations have been published that estimate the potential effects of this bundling policy.

We developed a pharmacy budget impact model capable of assessing the potential impact of the proposed bundled PPS rate on the budget available to Medicare organizations for the treatment of patients undergoing dialysis and receiving phosphate binders among Medicare Part D beneficiaries. In anticipation of the 2016 implementation, we utilized the model to estimate the budgetary impact associated with the integration of Part D drugs into the bundled PPS on a large dialysis organization setting in the United States. In August 2013, patent protection of sevelamer hydrochloride expired, which is likely to be followed by lanthanum carbonate in the near future. Alterations of phosphate binder market shares and shifts from branded to generic binders may impact treatment patterns of patients with ESRD. Therefore, we also used the model to evaluate potential changes to the budgetary impact under various phosphate binder market share scenarios between 2013 and 2016.

\section{Methods}

\section{Concept and Development of the Budget Impact Model}

An interactive budget impact model was developed using Microsoft Excel 2010 (Microsoft Corporation, Redmond, WA). This model incorporated the effect of Medicare payment changes and determined the potential economic implications to large dialysis organizations associated with the use of phosphate binders. Evaluations focused on the budget impact of the integration of current Part D drugs, specifically phosphate binders, into the PPS. The model estimated the budget impact of the Medicare payment changes in 2016, compared with 2013 and 2015, through the calculation of the total annual reimbursement costs (currently Part B and Part D), oral-only renal medication costs (Part D), and phosphate binder costs.

\section{Model Assumptions}

The budget impact model is based on the following assumptions.

- Within the new bundled rate, oral renal therapy medications (i.e., phosphate binders, cinacalcet, and oral vitamin D) will be reimbursed at $\$ 35.00$ per in-center dialysis session. After exclusion of oral vitamin $\mathrm{D}$, which has been included in the bundle since 2011, oral-only renal medications (phosphate binders and cinacalcet) will be reimbursed at $\$ 33.44$ per dialysis session $(\$ 35.00-\$ 1.56=\$ 33.44)$. The $\$ 33.44$ assumption is aligned with market expectations because it is within the rate proposed for oral renal reimbursement by CMS ( $\$ 14.00-\$ 1.56=\$ 12.44)$ and renal organizations $(\$ 45.00-\$ 1.56=\$ 43.44){ }^{13}$

- Patients will continue to receive 1 phosphate binder without switching to another phosphate binder during the study period (12 months).

- The incidence and prevalence of dialysis will remain constant on an annual basis, and new dialysis patients and those who die will each spend an average of 6 months in the model. Individuals who are hospitalized will not receive treatment via a dialysis organization during their hospital stay and have a corresponding decrease in the number of patient-years on dialysis.

- Dialysis centers will attempt to spend less than the amount of bundled reimbursement (including phosphate binders) per dialysis session and provide care to maximize the number of patients healthy enough to return for outpatient dialysis. Regardless of phosphate binder expenses, large dialysis centers will be reimbursed at a set rate for bundled dialysis services and renal medications. The expenses for cinacalcet (base \$13.80) per dialysis session have been inflated for annual cost adjustments between 2013 and 2016.

- Generics of sevelamer hydrochloride and lanthanum carbonate will become available in 2015 and cost $65 \%$ of the price of branded phosphate binders. It has been reported that when a generic drug is launched in the U.S. market at the time a patent expires, it is usually priced at around 30\% less than the original branded drug. ${ }^{18}$ 
FIGURE 1 Target Population Included in Economic Model

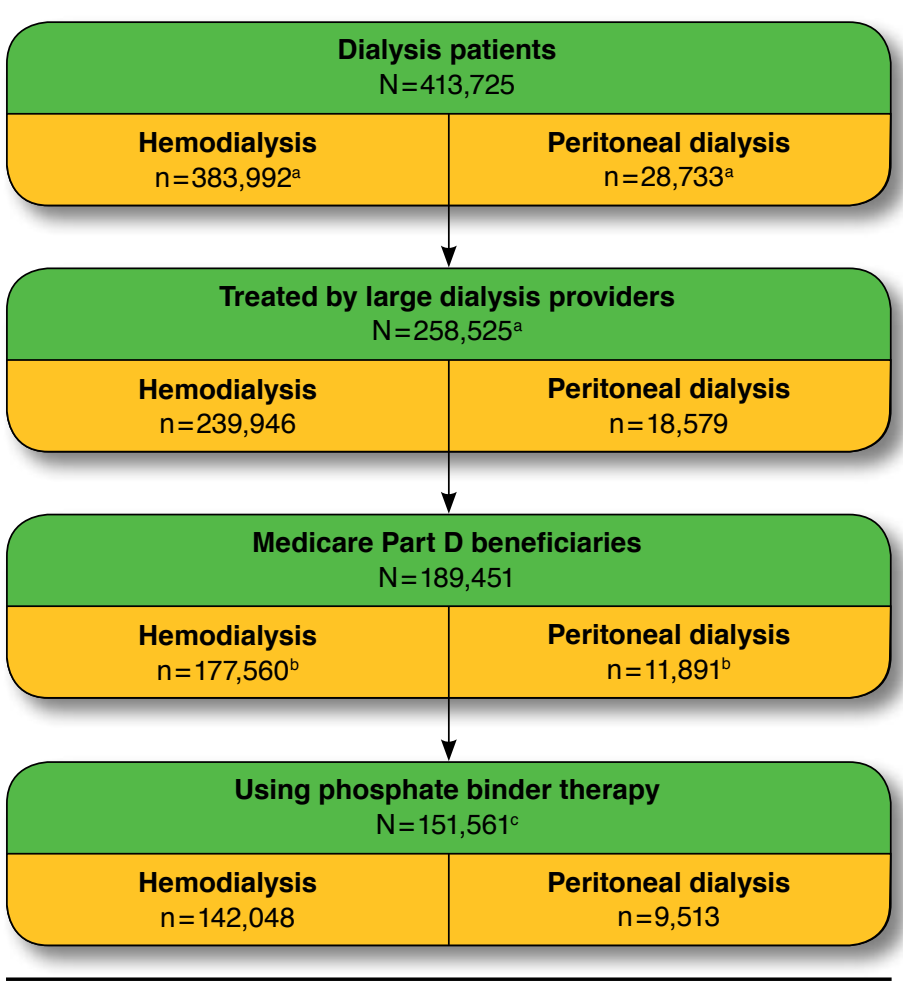

Note: Patient numbers were taken from the USRDS 2012 Annual Data Report. ${ }^{7}$ $80 \%$ of patients were estimated to use phosphate binders.

aFrom the USRDS 2012 Annual Data Report. ${ }^{7}$

b74\% of hemodialysis patients and 64\% of peritoneal dialysis patients are on Medicare Part D.

'Large dialysis organization estimate (DaVita).

USRDS = U.S. Renal Data System.

\section{Model Inputs}

Patient Population. The target population of the model was patients with ESRD who were Medicare Part D beneficiaries, were receiving phosphate binders, and were being treated by a large dialysis organization. Population estimates were based on 2010 data obtained from the 2012 USRDS annual report for patients who were treated in a large dialysis center and who received phosphate binders ( $80 \%$ of treated patients; see Figure 1$)^{7}$ There are 3 large dialysis centers in the United States: DaVita, Dialysis Clinic Inc., and Fresenius, where 258,525 dialysis patients were treated in 2010. It was estimated that patients have a mean of 140 in-center dialysis sessions per year ${ }^{19}$ and that $74 \%$ of hemodialysis patients and $64 \%$ of peritoneal dialysis patients are on Medicare Part D. ${ }^{7}$ The number of patientyears on dialysis was predicted based on mortality, adjusted depending on phosphate binder utilization and associated mortality:20 days not at the dialysis center due to hospitalization, based on mean hospital days: ${ }^{7}$ and risk reductions of

\begin{tabular}{l|c|c}
\hline TABLE 1 & $\begin{array}{l}\text { Current (2013) Estimated Phosphate } \\
\text { Binder Costs Reimbursed by Medicare } \\
\text { Part D and Market Shares (Large } \\
\text { Dialysis Organization Utilization Data) }\end{array}$ \\
\hline & $\begin{array}{c}\text { Adjusted Drug } \\
\text { Cost Per Daya }(\$)\end{array}$ & $\begin{array}{c}\text { Market Share, } \\
\text { \% Utilization }\end{array}$ \\
\hline Lanthanum carbonatec $^{\mathrm{b}}$ & 13.01 & 10.97 \\
\hline Sevelamer hydrochloride $^{\mathrm{d}}$ & 13.33 & 10.92 \\
\hline Sevelamer carbonate $^{\mathrm{e}}$ & 14.86 & 48.71 \\
\hline Calcium acetate $^{\mathrm{f}}$ & 5.12 & 2.80 \\
\hline Generic calcium acetate $^{\text {Dar }}$ & 3.53 & 26.61 \\
\hline
\end{tabular}

Note: Binder costs are based on 2008 and 2010 Part D data from the USRDS 2012 Annual Data Report. ${ }^{7}$

aUSRDS, adjusted for $6 \%$ inflation and $70 \%$ adherence. $^{7}$

${ }^{b}$ DaVita data (2011 calendar year).

cFOSRENOL (Shire Pharmaceuticals).

${ }^{d}$ Renagel (Sanofi).

eRenvela (Sanofi).

fPhosLo (Fresenius Medical Care).

USRDS = U.S. Renal Data System.

phosphate binders relative to one another (Appendix A, available in online article). ${ }^{21,22}$

Phosphate Binder Utilization Rates. Current (2013) relative utilization rates of calcium-, sevelamer-, and lanthanum-based phosphate binders (Table 1) were based on 2011 drug utilization data from a large dialysis organization setting (Shire internal data). A $70 \%$ rate of adherence to phosphate binders was assumed. ${ }^{23}$ It was assumed that the $32 \%$ of patients undergoing dialysis who received phosphate binder therapy received cinacalcet (Shire internal data).

Phosphate Binder Costs. Medicare reimbursements for various phosphate binders were based on 2008 and 2010 Part D data from the 2012 USRDS annual report (Table 1). ${ }^{7}$ Costs were adjusted to 2013 U.S. dollars using an inflation rate of $6 \%$ per year. Future Medicare PPS reimbursements were estimated based on (a) a \$240.36 reimbursement (2013 Medicare Part B) and a \$239.33 reimbursement (2015-2016 Medicare Part B) for dialysis, lab tests, injectable drugs, and oral vitamin D per dialysis session, ${ }^{8}$ and (b) an assumed additional base case reimbursement of $\$ 33.44$ per dialysis session for oral-only renal medications including phosphate binders and cinacalcet. Projected phosphate binder costs in 2015 and 2016 were based on 2013 costs and market shares and were adjusted for 6\% inflation.

Sensitivity and Scenario Analyses. The base case analysis was conducted with the current utilization and costs of phosphate binders. One-way sensitivity analyses were performed for 2016 using ranges for phosphate binder adherence $( \pm 20 \%$ of $70 \%$; $56 \%$ $84 \%$ ), inflation rate (4\%-8\%), and reimbursement amounts for the bundled PPS $( \pm 20 \%$ of $\$ 34.44 ; \$ 26.75-\$ 40.13)$. In addition, 


\section{TABLE 2 Phosphate Binder Costs}

\begin{tabular}{|c|c|c|c|}
\hline \multicolumn{4}{|c|}{$\begin{array}{l}\text { A. Estimated Phosphate Binder Reimbursement Within the Medicare } \\
\text { Bundled PPS to a Large Dialysis Organization in } 2015 \text { and } 2016 \\
\text { Compared with Reimbursements in } 2013 \text { (When Part B and Part D } \\
\text { Are Reimbursed Separately) }\end{array}$} \\
\hline & $\begin{array}{c}\text { Current } \\
\text { Scenario (2013) }\end{array}$ & $\begin{array}{c}\text { Predicted } \\
\text { Scenario }(2015)\end{array}$ & $\begin{array}{c}\text { Predicted } \\
\text { Scenario (2016) }\end{array}$ \\
\hline $\begin{array}{l}\text { Current Part B } \\
\text { reimbursement }{ }^{\mathrm{a}}(\$)\end{array}$ & 240.36 & 239.33 & 239.33 \\
\hline $\begin{array}{l}\text { Oral-only renal } \\
\text { medication } \\
\text { reimbursement }(\$)\end{array}$ & 42.92 & 48.03 & 33.44 \\
\hline $\begin{array}{l}\text { Phosphate binder } \\
\text { reimbursement (\$) }\end{array}$ & 29.12 & 32.53 & 17.01 \\
\hline $\begin{array}{l}\text { Cinacalcet } \\
\text { reimbursement }(\$)\end{array}$ & 13.80 & 15.50 & 16.43 \\
\hline $\begin{array}{l}\text { Reimbursement } \\
\text { estimate }^{c}(\$)\end{array}$ & 283.28 & 287.36 & 272.77 \\
\hline $\begin{array}{l}\text { Total phosphate binder } \\
\text { reimbursement }(\$)\end{array}$ & $576,461,842$ & $643,804,665$ & $336,568,738$ \\
\hline
\end{tabular}

B. Projected Phosphate Binder Costs Based on Current

(2013) Market Shares

\begin{tabular}{|c|c|c|c|}
\hline & $\begin{array}{c}\text { Current } \\
\text { Scenario (2013) }\end{array}$ & $\begin{array}{c}\text { Predicted } \\
\text { Scenario }(2015)\end{array}$ & $\begin{array}{c}\text { Predicted } \\
\text { Scenario (2016) }\end{array}$ \\
\hline Current Part B costs ${ }^{\mathrm{a}}(\$)$ & 240.36 & 239.33 & 239.33 \\
\hline $\begin{array}{l}\text { Oral-only renal } \\
\text { medication }{ }^{b} \text { costs }(\$)\end{array}$ & 42.92 & 48.03 & 50.92 \\
\hline $\begin{array}{l}\text { Phosphate binder } \\
\text { costs }(\$)\end{array}$ & 29.12 & 32.53 & 34.48 \\
\hline Cinacalcet costs $(\$)$ & 13.80 & 15.50 & 16.43 \\
\hline Cost estimated $(\$)^{\mathrm{d}}$ & 283.28 & 287.36 & 290.25 \\
\hline $\begin{array}{l}\text { Total phosphate } \\
\text { binder cost }(\$)\end{array}$ & $576,461,842$ & $643,804,665$ & $682,432,945$ \\
\hline
\end{tabular}

aFixed value in the model.

${ }^{b}$ Phosphate binders and cinacalcet.

${ }^{c}$ Current Part B reimbursement + phosphate binder reimbursement + cinacalet

reimbursement.

${ }^{d}$ Current Part B cost + phosphate binder cost + cinacalet cost.

PPS = prospective payment system

scenario analyses were conducted using a variety of potential future alterations in phosphate binder percentage utilization.

\section{Results}

\section{Predicted PPS Reimbursements}

The target population comprised an estimated 151,561 patients in 2013 (Figure 1). In 2013 and 2015 the oral-only renal medication reimbursements were estimated at $\$ 42.92$ and $\$ 48.03$, respectively (Table $2 \mathrm{~A}$ ), based on current market shares and costs (Table 1). These estimates equaled the medication costs (Table 2B) before the integration of Part D drugs into the PPS. The 2013 estimated reimbursement for cinacalcet was $\$ 13.80$ per dialysis session. This was calculated based on the weekly cost of cinacalcet currently reimbursed by Medicare divided by 2.68 dialysis sessions per week, with an assumption that $32 \%$ of patients in this model utilized cinacalcet, and adjusted for
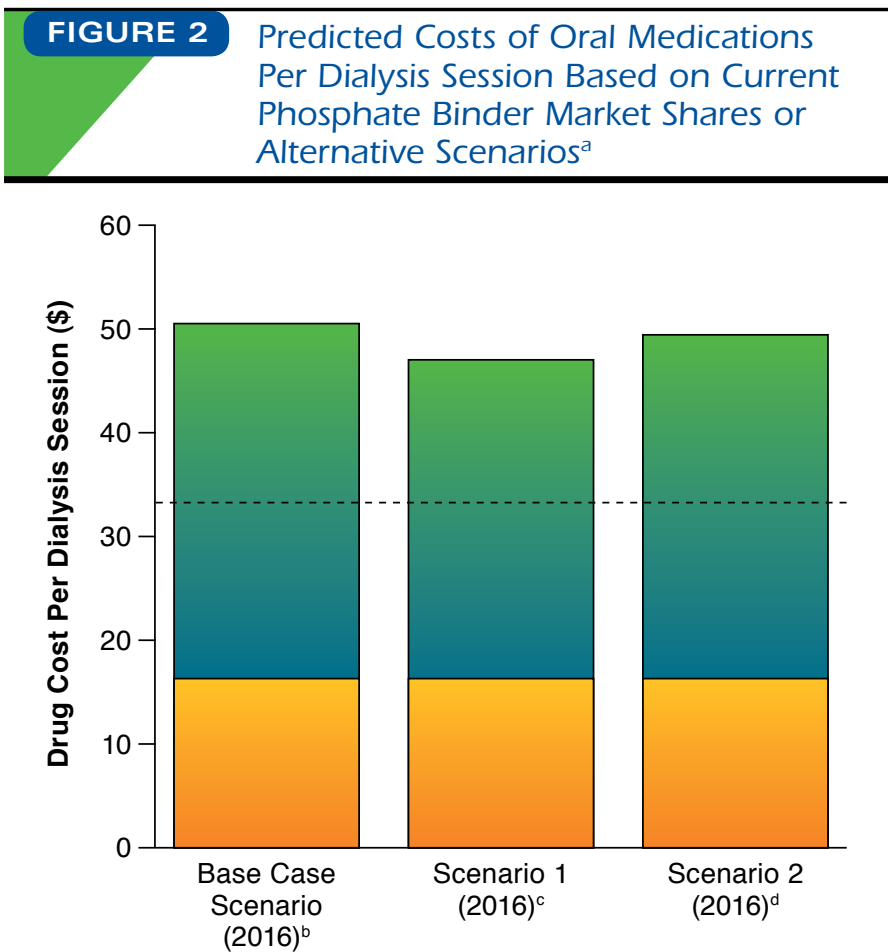

\section{Phosphate binder costs Cinacalcet costs - - - \$33.44 reimbursement}

aCompared with a $\$ 33.44$ oral medication reimbursement rate.

bBase case (2016): costs based on current phosphate binder market shares (2013). cScenario 1 (2016): 20\% shift in market share from branded sevelamer hydrochloride to generic sevelamer hydrochloride between 2013 and 2016.

dScenario 2 (2016): 20\% shift in market share from sevelamer carbonate to lanthanum carbonate between 2013 and 2016.

$6 \%$ inflation and $70 \%$ adherence. ${ }^{7}$ Phosphate binder medication cost estimates for 2013 were $\$ 29.12$ per dialysis session (weekly cost of medications currently reimbursed by Medicare divided by an estimated 2.68 dialysis sessions per week). ${ }^{7}$ Based on the assumed reimbursement of $\$ 33.44$ per dialysis session, reimbursement costs for cinacalcet in 2016 were predicted at $\$ 16.43$, leaving $\$ 17.01$ available for phosphate binder reimbursements (Table 2A). Total anticipated PPS reimbursement for phosphate binders was estimated at $\$ 576,461,842$ in 2013 and $\$ 643,804,665$ in 2015 , but this decreased to $\$ 336,568,738$ in 2016 following introduction of the new $\$ 33.44$ bundled reimbursement rate for oral-only renal medications (Table 2A).

\section{Anticipated Costs Based on Current Phosphate Binder Market Shares (Base Case Analysis)}

Future costs of phosphate binders were estimated in the budget impact model at $\$ 643,804,665$ in 2015 and $\$ 682,432,945$ in 2016, based on inflation (Table 2B). Estimated phosphate 


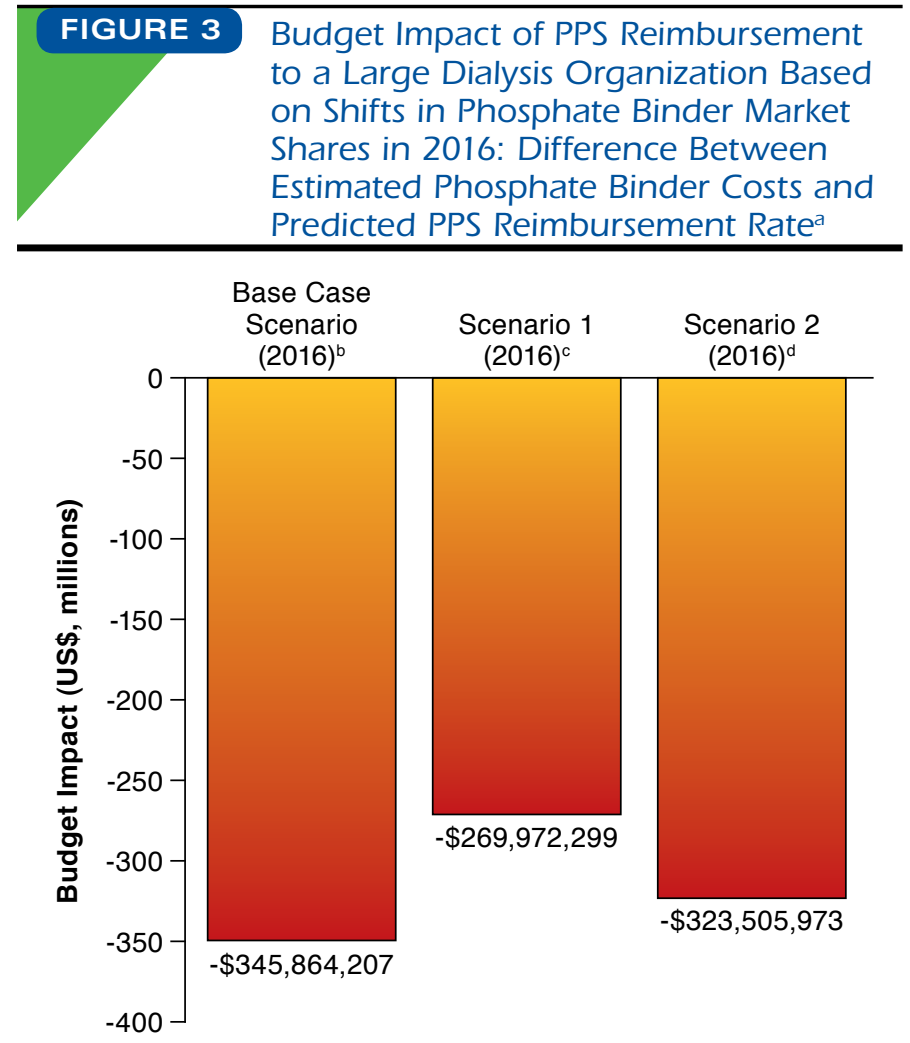

a Based on $\$ 33.44$ per dialysis session for oral medications.

bBase case scenario (2016): based on current (2013) phosphate binder market shares.

'Scenario 1 (2016): 20\% shift in market share from branded sevelamer hydrochloride to generic sevelamer hydrochloride between 2013 and 2016.

dScenario 2 (2016): 20\% shift in market share from sevelamer carbonate to lanthanum carbonate between 2013 and 2016.

PPS = prospective payment system

binder costs were found to increase to $\$ 34.48$ per dialysis session in 2016 (based on 6\% inflation per year) based on scenarios of continued 2013 phosphate binder market shares. This cost is double the predicted amount available for phosphate binder reimbursement costs within the PPS (\$17.01).

A $\$ 33.44$ reimbursement rate for all oral-only renal medications (with $\$ 17.01$ being allocated for phosphate binders) within the PPS, therefore, is insufficient to cover dialysisrelated drug costs in this 2016 scenario (Figure 2). If current phosphate binder market shares were to remain the same in 2016 , a PPS reimbursement of $\$ 50.92$ ( $\$ 34.48$ for phosphate binders and $\$ 16.43$ for cinacalcet) would be necessary to cover the predicted oral-only renal medication costs of large dialysis organizations (Table 2B). Based on these estimates, a reimbursement rate of $\$ 33.44$ per dialysis session for oral-only renal medications would lead to a potential budget shortfall of $\$ 345,864,207$ in phosphate binder funds in 2016 (Figure 3).

\section{Sensitivity and Scenario Analyses}

One-way sensitivity analyses show that phosphate binder drug costs per dialysis session in 2016 would range from $\$ 27.59$ to $\$ 41.38$, and the budget impact would range from a shortfall of $\$ 144,331,380$ to $\$ 547,397,035$ (compared with the base case shortfall of $\$ 345,864,207$ ) over a phosphate binder adherence rate range of $66 \%-84 \%$ (Figure 4 ). Phosphate binder drug costs per dialysis session would range from $\$ 29.61$ to $\$ 40.04$, and the budget impact would range from a shortfall of $\$ 219,861,182$ to $\$ 487,800,320$ across an inflation rate range of $4 \%-8 \%$. Over a bundled PPS reimbursement rate range of $\$ 26.75$ $\$ 40.13$, phosphate binder drug costs per dialysis session were $\$ 34.48$, and the budget impact shortfall would range from $\$ 246,910,869$ to $\$ 444,817,546$. Model scenarios are shown in Appendices B-D (available in online article).

\section{Discussion}

We developed an interactive budget impact model to estimate the potential economic impacts of the new Medicare bundled ESRD PPS reimbursement. The model was also capable of estimating the budgetary impact of the proposed PPS reimbursement rate under various phosphate binder market scenarios based on potential future shifts from current market conditions. To our knowledge, this study constitutes the first budgetary impact assessment of the Medicare bundled reimbursement rate from a large dialysis organization perspective. At the time of this study, the implementation of this payment reform was expected to be effective in 2016.

The budget impact model suggested that estimated phosphate binder costs (based on 2013 utilization data) in 2016 (\$34.48) may be almost twice that of the estimated PPS reimbursement rate available for phosphate binders (\$17.01). Based on the current data available, our model predicted that the projected \$33.44 PPS reimbursement rate for oral-only renal medications would be insufficient to cover these costs. Instead, it suggested that a 2016 reimbursement rate closer to $\$ 50.91$ per dialysis session ( $\$ 34.48$ phosphate binders; $\$ 16.43$ cinacalcet) may be required simply to fund the current utilization mix of phosphate binders. Medicare PPS reimbursements were estimated based on a $\$ 240.36$ reimbursement for dialysis, lab tests, injectable drugs, and oral vitamin D (2013, Medicare Part B), and the 2015 PPS base rate reimbursement would be $\$ 239.33$. It should be noted, however, that change in reimbursement for Part B between 2013 and 2016 would not affect our results because this study focused on the budget impact shortfall relating to phosphate binder use.

A 20\% shift in the market share from sevelamer carbonate to lanthanum carbonate or a $20 \%$ reduction in the market share of sevelamer hydrochloride to a generic formulation in 2016 resulted in similar costs to those estimated for the base case 2016 scenario based on the current (2013) market share mix 
of phosphate binders. Several other scenarios based on various potential phosphate binder market share shifts from 2013 to 2016, and sensitivity analyses also indicated that a large dialysis organization may be challenged to manage phosphate binder expenditures within the Medicare bundled rate structure. The scenario analysis indicated that unless calcium-based phosphate binder use increases significantly (by $70 \%$ ), phosphate binder cost per dialysis session would not meet the phosphate binder reimbursement rate. Our model found that the utilization-weighted mortality and number of hospital days increased proportionally as calcium salt utilization increased (Appendix $\mathrm{B}$, available in online article). Although calcium-based binders are relatively inexpensive, calcium salts have been associated with an increased risk of hypercalcemia and vascular calcification. ${ }^{24,25}$ The National Kidney Foundation's Kidney Disease Outcomes Quality Initiative recommends that the daily calcium intake from phosphate binders should not exceed 1,500 milligrams per day. ${ }^{4}$ Patient quality of care may therefore be compromised under such low medication cost scenarios. When implementing new medical payment systems, it is important to ensure that adequate measures are in place to evaluate the outcomes and to maintain the standard of patient care.

The outputs from our model support concern for potential undertreatment of patients with ESRD and the management of new trade-offs affecting facilities and patient outcomes under the new Medicare payment approach. ${ }^{14,15}$ Despite the early observations by the Study to Evaluate the Prospective Payment System Impact on Small Dialysis Organizations, ${ }^{17}$ which suggested that the proportion of patients treated with phosphate binders increased following implementation of the 2011 PPS, our model indicated that this trend is unlikely to continue following the integration of the Part D medications into a PPS bundle.

Our model is a useful and innovative effort to evaluate the budgetary impact of the new bundled PPS. It is a valuable tool for evaluating the adequacy of a PPS $\$ 33.44$ reimbursement rate in providing the necessary oral-only renal medications to patients. In addition, our model estimated that the Medicare phosphate binder cost per dialysis session in 2013 was $\$ 29.12$. This translates to $\$ 339.72$ per patient per month (assuming 140 dialysis sessions per year), which is consistent with the 2012 USRDS report (phosphate binder costs for 2010 were $\$ 331.92$ per person per month). ${ }^{7}$ The predictions derived from our model are therefore aligned with the USRDS report. ${ }^{7}$ The estimates presented in this study are based on a large dialysis organization perspective; further research is required to investigate the economic impacts of the integration of phosphate binders in the bundle reimbursement on smaller organizations because they are more likely to be susceptible to financial implications of the PPS than large organizations. This study supports the recent delay of the bundling implementation for oral-only renal medications, which will give CMS time to further evaluate the reimbursement rate and implement a policy that ensures access to care while recognizing the need for continued quality of care in this population. Our findings provide important information to stakeholders concerning this policy, including CMS, since this study provides incremental data that could inform a potentially more reasonable reimbursement rate based on the recent utilization and costs 
of phosphate binders and taking into account adherence, hospitalization, and mortality.

\section{Limitations}

Our evaluation may be limited because the model is developed from a mix of available data sources not necessarily intended for research purposes. Another potential limitation is that the results are based on predictions of the Medicare bundled reimbursement rate for both dialysis-related services and oralonly renal medications. In order to predict future costs, the model has to be based on a variety of assumptions that may also potentially limit our economic evaluations. Additionally, the treatment efficacy associated with phosphate binders (i.e., reduced risks of hospital days and mortality) was derived from 1-year outcomes. Furthermore, we did not consider patients' copayments, dialysis organizations' purchasing prices for phosphate binders, or the ESRD Quality Incentive Program, which may also affect drug utilization and costs. ${ }^{14}$ Patients' out-ofpocket costs have the potential to change because drugs currently covered under Part D will be integrated into Medicare Part B. Large dialysis organizations' drug purchasing prices may vary from those in Medicare Part D, and the ESRD Quality Incentive Program may affect their behavior. There is also uncertainty relating to the potential direct and indirect effects of changing phosphate binder utilization and costs based on dialysis organization behavior after the implementation of a bundled system. Lastly, this study was conducted under the assumption of policy implementation in 2016, although as a part of Health Provisions in the Protecting Access to Medicare Act of 2014, inclusion of oral renal drugs into the bundled payment system has been further delayed until 2024. However, this timely information has relevance to policy decision makers who will reevaluate this program and guide its decisions with evidence of the potential impact of the bundled PPS on the budget available for large dialysis centers.

\section{Conclusions}

The findings from this budget impact model suggest that large dialysis organizations may be confronted with important budgetary implications within a bundled PPS system for renal medications. More specifically, they face great challenges to manage phosphate binder expenditures within the current estimated Medicare 2016 bundled reimbursement rate for oral renal medications. The new PPS system may influence future treatment selection, patterns of medication use, and health outcomes in patients with ESRD. Inadequate reimbursement rates for oral renal medications may lead to unintended patient consequences, such as increased mortality and additional hospitalization. Therefore, to ensure that renal patients have sufficient access to phosphate binders, a higher renal oral medication reimbursement rate than that anticipated in the most recent proposal for the new Medicare PPS may be required.

\section{Authors}

HAESUK PARK, PhD, is Assistant Professor, Department of Pharmaceutical Outcomes \& Policy, University of Florida College of Pharmacy, Gainesville, Florida; KAREN L. RASCATI, PhD, is Professor, The University of Texas at Austin; and MICHAEL S. KEITH, PhD, PharmD, was Head, Global Health Economics, Shire Development, LLC, Wayne, Pennsylvania.

AUTHOR CORRESPONDENCE: Haesuk Park, PhD, Assistant Professor, University of Florida College of Pharmacy, Dept. of Pharmaceutical Outcomes \& Policy, 1225 Center Dr., HPNP 3325, Gainesville, FL 32610. Tel.: 352.273.6261; Fax: 352.273.6270; E-mail:hpark@cop.ufl.edu.

\section{DISCLOSURES}

Rascati and Park received research funding for this study from Shire Development, LLC. Keith was an employee of Shire Development at the time this study was conducted and owned stock in Shire.

Study concept and design were contributed by Rascati, Park, and Keith. Park took the lead in data collection, along with Rascati and Keith. All authors contributed equally to data analysis. The manuscript was written primarily by Park, along with Rascati and Keith. Rascati took the lead in manuscript revision, along with Park and Keith.

\section{ACKNOWLEDGMENTS}

We thank Vivienne Stein-Rostaing, PhD, of PharmaGenesis London, who was funded by Shire to provide editorial assistance for this manuscript.

\section{REFERENCES}

1. Kestenbaum B, Sampson JN, Rudser KD, et al. Serum phosphate levels and mortality risk among people with chronic kidney disease. J Am Soc Nephrol. 2005;16(2):520-28.

2. Achinger SA, JC Ayus. Left ventricular hypertrophy: is hyperphosphatemia a risk factor in dialysis patients? J Am Soc Nephrol. 2006;17(12 Suppl 3):S255-61.

3. Block GA, Klassen PS, Lazarus JM, Ofsthun N, Lowrie EG, Chertow GM. Mineral metabolism, mortality, and morbidity in maintenance hemodialysis. J Am Soc Nephrol. 2004;15(8):2208-18.

4. National Kidney Foundation. K/DOQI clinical practice guidelines for bone metabolism and disease in chronic kidney disease. Am J Kidney Dis. 2003;42(4 Suppl 3):S1-202

5. Kidney Disease: Improving Global Outcomes (KDIGO) CKD-MBD Work Group. KDIGO clinical practice guideline for the diagnosis, evaluation, prevention, and treatment of chronic kidney disease-mineral and bone disorder (CKD-MBD). Kidney Int. 2009;76:S1-2.

6. St Peter WL. Chronic kidney disease and Medicare. J Manag Care Pharm. 2007;13(9 Suppl D):S13-18. Available at: http://www.amcp.org/data/jmcp/ JMCPSupp\%20D_Dec07_S13-S18.pdf.

7. U.S. Renal Data System. USRDS 2012 annual data report: atlas of chronic kdney disease and end-stage renal disease in the United States. National Institutes of Health, National Institute of Diabetes and Digestive and Kidney Diseases, Bethesda, MD; 2012. Available at: http://www.usrds.org/atlas12. aspx. Accessed April 22, 2015.

8. Centers for Medicare \& Medicaid Services, U.S. Department of Health and Human Services. Medicare program; end-stage renal disease prospective payment system. Fed Regist. 2014;79(133):40208-315. 
9. Winkelmayer WC. Potential effects of the new Medicare prospective payment system on drug prescription in end-stage renal disease care. Blood Purification. 2011;31(1-3):66-69.

10. Centers for Medicare \& Medicaid Services, U.S. Department of Health and Human Services. Medicare program; end-stage renal disease prospective payment system. Final rule. Fed Regist. 2010;75(155):49029-214.

11. Feldman R, Desmarais M, Muller J. Orals in the bundle: a policy framework. Clin J Am Soc Nephrol. 2013;8(6):1043-47.

12. U.S. House of Representatives. Summary of health provisions in the protecting access to Medicare Act of 2014. March 2014. Available at: http://democrats.energycommerce.house.gov/sites/default/files/documents/SummaryHR-4302-SGR-Medicare-2014-3-26.pdf. Accessed April 22, 2015.

13. Johnson DS, Meyer KB, Johnson HK. The 2011 ESRD prospective payment system and the survival of an endangered species: the perspective of a not-for-profit medium-sized dialysis organization. Am J Kidney Dis. 2011;57(4):553-55.

14. Iglehart JK. Bundled payment for ESRD—including ESAs in Medicare's dialysis package. N Engl J Med. 2011;364(7):593-95.

15. Robinson B, Fuller D, Zinsser D, et al. The Dialysis Outcomes and Practice Patterns Study (DOPPS) Practice Monitor: rationale and methods for an initiative to monitor the new US bundled dialysis payment system. Am J Kidney Dis. 2011;57(6):822-31.

16. Hornberger J, Hirth RA. Financial implications of choice of dialysis type of the revised Medicare payment system: an economic analysis. Am J Kidney Dis. 2012;60(2):280-87.
17. Brunelli SM, Monda KL, Burkart JM, et al. Early trends from the Study to Evaluate the Prospective Payment System Impact on Small Dialysis Organizations (STEPPS). Am J Kidney Dis. 2013;61(6):947-56.

18. OXERA. Fundamental review of the generic drugs market. U.S. Department of Health. July 2001. Available at: http://www.oxera.com/Oxera/ media/Oxera/downloads/reports/Fundamental-review-of-generic-drugsindustry.pdf?ext=.pdf. Accessed April 22, 2015.

19. Sullivan JD. In a bundling era, finding a fair price for ESRD services. Nephrol News Issues. 2007;21(4):37, 39-40.

20. Manns B, Klarenbach S, Lee H, Culleton B, Shrive F, Tonelli M. Economic evaluation of sevelamer in patients with end-stage renal disease. Nephrol Dial Transplant. 2007;22(10):2867-78.

21. Taylor MJ, Elgazzar HA, Chaplin S, Goldsmith D, Molony DA. An economic evaluation of sevelamer in patients new to dialysis. Curr Med Res Opin. 2008;24(2):601-08

22. Park H, Rascati KL, Keith MS, Hodgkins P, Smyth M, Goldsmith D, Akehurst R. Cost-effectiveness of lanthanum carbonate versus sevelamer hydrochloride for the treatment of hyperphosphatemia in patients with endstage renal disease: a U.S. payer perspective. Value Health. 2011;14(8):1002-09.

23. Chiu YW, Teitelbaum I, Misra M, De Leon EM, Adzize T, Mehrotra R. Pill burden, adherence, hyperphosphatemia, and quality of life in maintenance dialysis patients. Clin J Am Soc Nephrol. 2009;4(6):1089-96.

24. Hutchinson AJ, Smith CP, Brenchley PE. Pharmacology, efficacy and safety of oral phosphate binders. Nat Rev Nephrol. 2011;7(10):578-89.

25. Qunibi WY, Moustafa M, Kessler P, et al. Treatment of hyperphosphatemia in hemodialysis patients: the Calcium Acetate Renagel Evaluation (CARE Study). Kidney Int. 2004;65(5):1914-26. 
Managing Oral Phosphate Binder Medication Expenditures Within the Medicare Bundled End-Stage Renal Disease Prospective Payment System: Economic Implications for Large U.S. Dialysis Organizations

\section{APPENDIX A Model Inputs}

\begin{tabular}{|c|c|c|}
\hline Hospital Days & Input (Days) & Source \\
\hline Mean hospital days per year among Medicare beneficiaries & 12.05 & USRDS 2012 Annual Data Report ${ }^{7}$ \\
\hline Calcium acetate & 13.84 & Current calcium utilization (39\%) adjusted hospital days ${ }^{7}$ \\
\hline Sevelamer & 10.93 & 13.84 days $\times 0.79$ (risk reduction of sevelamer vs. calcium) ${ }^{20}$ \\
\hline Lanthanum carbonate & 10.82 & 10.93 days $\times 0.99$ (risk reduction of lanthanum vs. sevelamer) 22 \\
\hline Mortality & Input (\%) & Source \\
\hline Annual mean mortality among Medicare beneficiaries & 35.44 & USRDS 2012 Annual Data Report ${ }^{7}$ \\
\hline Calcium acetate & 37.55 & Current calcium utilization (39\%) adjusted mortality ${ }^{7}$ \\
\hline Sevelamer & 34.17 & $37.55 \% \times 0.91$ (risk reduction of sevelamer vs. calcium) ${ }^{19}$ \\
\hline Lanthanum carbonate & 33.49 & $34.17 \% \times 0.98$ (risk reduction of lanthanum vs. sevelamer) 22 \\
\hline
\end{tabular}

\section{APPENDIX B Model Scenarios}

Changes to phosphate binder market shares were adjusted in the model allowing investigation of a variety of potential future scenarios. We specifically explored the effects of 2 different market share scenarios (scenarios 1 and 2), based on the expected market shifts and market prices due to the expiration of sevelamer hydrochloride and lanthanum carbonate and the impact of this on the annual phosphate binder costs to a large dialysis organization expected in 2016.

\section{Scenario 1}

A generic formulation of sevelamer hydrochloride is expected to be available in 2015. We manipulated the model according to a potential future scenario involving a 20\% shift in phosphate binder market share from branded to generic sevelamer hydrochloride between 2013 and 2016 . This produced an estimated phosphate binder cost of $\$ 30.65$ per dialysis session (Appendix C). This is lower than the 2016 cost estimated under the base case scenario ( $\$ 34.48$ ); however, a $\$ 33.44$ reimbursement rate for oral-only renal medications ( $\$ 17.01$ for phosphate binders) would still be insufficient to cover dialysis-related costs in this scenario (Figure 2 in text). In this scenario, estimated total expenditure $(\$ 606,541,037)$ was slightly lower than the 2016 base case scenario $(\$ 682,432,945$, Appendix C). According to these estimates, a reimbursement rate of $\$ 33.44$ per dialysis session for oral-only renal medications would lead to a shortfall of $\$ 269,972,299$ for large dialysis organizations in 2016 (Figure 3 in text).

\section{Scenario 2}

We investigated a scenario based on a 20\% shift in market share from sevelamer carbonate to lanthanum carbonate between 2013 and 2016 . A $20 \%$ increase in the share of lanthanum carbonate and corresponding decrease in sevelamer carbonate share in 2016 resulted in an estimated total phosphate binder cost of $\$ 33.34$ per dialysis session, which is only slightly lower than the 2016 estimate under the base case scenario (\$34.48; Appendices C and D). A $\$ 33.44$ reimbursement rate for oral renal medications would therefore also be insufficient to cover dialysis-related costs in this scenario (Figure 2 in text). The total budget impact of this scenario $(\$ 660,343,728)$ was similar to the 2016 base case scenario $(\$ 682,432,945$ based on current market shares), leading to a shortfall of $\$ 323,505,973$ (Figure 4 in text).

\section{Additional Scenarios}

We utilized the model to investigate the budgetary impact of other scenarios based on a variety of market share shifts from 2013 to 2016 (scenarios 3-6, Appendix D). These scenarios generated estimates of phosphate binder costs between $\$ 25.33$ and $\$ 32.57$. A $\$ 33.44$ reimbursement rate for oral-only renal medications was consistently found to be insufficient to cover oral renal medication costs across all of these market scenarios, leading to shortfalls of between $\$ 164,706,535$ and $\$ 307,918,253$ (Appendix D).

The model was also manipulated to investigate budgetary impact scenarios using anticipated costs based on 2016 phosphate binder utilization share (calcium acetate utilization: 30\%-70\%; data not presented). In these scenarios, anticipated costs of phosphate binders were lower than in the scenarios based on market shifts; however, the majority also indicated that a $\$ 33.44$ reimbursement rate for oral-only renal medications would still be insufficient to cover dialysis-related costs, leading to shortfalls ranging from $\$ 911,511$ to $\$ 137,936,110$. Only 1 scenario (70\% generic calcium acetate $+30 \%$ generic sevelamer hydrochloride) met the PPS phosphate binder reimbursement rate (\$17.01), with anticipated drug costs of $\$ 15.71$. This scenario therefore led to savings of $\$ 25,429,981$. However, the model found that this scenario was associated with increased utilization-weighted mortality (36.54\%) and number of hospital days (12.97 days) from an increased utilization of calcium acetate. 
APPENDIX C Model Scenario Analysis: Modeled Phosphate Binder Market Share Changes and Impact on Annual Predicted Phosphate Binder Costs to a Large Dialysis Organization

\begin{tabular}{|c|c|c|c|}
\hline & $\begin{array}{c}\text { Base Case Scenario } \\
(2016)^{\mathrm{a}}\end{array}$ & $\begin{array}{c}\text { Scenario } 1 \\
(2016)^{\mathrm{b}} \\
20 \% \text { SH }(B) \text { to } 20 \% \text { SH }(G)\end{array}$ & $\begin{array}{c}\text { Scenario } 2 \\
(2016)^{\mathrm{c}} \\
20 \% \text { SC (B) to } 20 \% \text { LC (B) }\end{array}$ \\
\hline Number of dialysis treatments PYPP & 140 & 140 & 140 \\
\hline Patient years on dialysis & 140,959 & 140,959 & 141,072 \\
\hline Total number of dialysis treatments & $19,790,668$ & $19,790,668$ & $19,806,486$ \\
\hline Current Part B cost $\mathrm{t}^{\mathrm{d}}$ & $\$ 239.33$ & $\$ 239.33$ & $\$ 239.33$ \\
\hline Oral-only renal medication cost & $\$ 50.92$ & $\$ 47.08$ & $\$ 49.77$ \\
\hline Phosphate binder cost & $\$ 34.48$ & $\$ 30.65$ & $\$ 33.34$ \\
\hline Cinacalcet cost & $\$ 16.43$ & $\$ 16.43$ & $\$ 16.43$ \\
\hline Cost estimate ${ }^{\mathrm{a}}$ & $\$ 272.77$ & $\$ 286.41$ & $\$ 289.10$ \\
\hline Total phosphate binder cost & $\$ 682,432,945$ & $\$ 606,541,037$ & $\$ 660,343,728$ \\
\hline
\end{tabular}

aBase case (2016): costs based on current phosphate binder market shares (2013).

bScenario 1 (2016): 20\% shift in market share from branded SH to generic SH between 2013 and 2016.

cScenario 2 (2016): 20\% shift in market share from SC to LC between 2013 and 2016.

${ }^{d}$ Current Part B cost + phosphate binder cost + cinacalcet cost.

$B=$ branded; $G=$ generic; $L C=$ lanthanum carbonate; $P Y P P=$ per year per person; $S C=$ sevelamer carbonate; $S H=$ sevelamer hydrochloride.

APPENDIX D Budget Impact of Model Scenarios Based on Current Phosphate Binder Market Shares (2013) to Anticipated 2016 Market Shares

\begin{tabular}{|c|c|c|}
\hline Scenario & $\begin{array}{c}\text { Phosphate Binder } \\
\text { Cost Per Dialysis } \\
\text { (2016), \$ }\end{array}$ & $\begin{array}{c}\text { Budget Impact Shortfall } \\
\text { in } 2016 \\
\text { (Reimbursement Spending), \$ }\end{array}$ \\
\hline Based on current market scenario (2013) & 34.48 & $345,864,207$ \\
\hline Based on $\$ 33.44$ reimbursement per dialysis session (2016) & 17.01 & 0 \\
\hline \multicolumn{3}{|c|}{ Alternative scenarios: market share shift from current market share (2013) to anticipated 2016 market share } \\
\hline Scenario $1: 20 \%$ SH (B) to $20 \%$ SH (G) & 30.65 & $269,972,299$ \\
\hline Scenario 2: $20 \%$ SC (B) to $20 \%$ LC (B) & 33.34 & $323,505,973$ \\
\hline Scenario 3: a. $10 \% \mathrm{SH}(\mathrm{B})+11 \% \mathrm{LC}(\mathrm{B})$ to $21 \% \mathrm{SH}(\mathrm{G})$ & 31.08 & $278,494,353$ \\
\hline b. $10 \% \mathrm{SH}(\mathrm{B})+11 \%$ LC (B) to $10 \% \mathrm{SH}(\mathrm{G})+11 \%$ LC (B) & 32.57 & $307,918,253$ \\
\hline Scenario 4: a. $20 \% \mathrm{SH}(\mathrm{B})+11 \% \mathrm{LC}(\mathrm{B})$ to $31 \% \mathrm{SH}(\mathrm{G})$ & 29.17 & $240,565,080$ \\
\hline b. $20 \% \mathrm{SH}(\mathrm{B})+11 \%$ LC (B) to $20 \% \mathrm{SH}(\mathrm{G})+11 \%$ LC (B) & 30.65 & $269,972,299$ \\
\hline Scenario 5: a. $30 \%$ SH (B) + 11\% LC (B) to $41 \%$ SH (G) & 27.25 & $202,635,808$ \\
\hline b. $30 \% \mathrm{SH}(\mathrm{B})+11 \% \mathrm{LC}(\mathrm{B})$ to $30 \% \mathrm{SH}(\mathrm{G})+11 \% \mathrm{LC}(\mathrm{B})$ & 28.73 & $232,026,345$ \\
\hline Scenario 6: a. $40 \%$ SH (B) + 11\% LC (B) to 51\% SH (G) & 25.33 & $164,706,535$ \\
\hline b. $40 \%$ SH (B) $+11 \%$ LC (B) to $40 \%$ SH $(\mathrm{G})+11 \%$ LC (B) & 26.81 & $194,080,391$ \\
\hline
\end{tabular}

